\title{
Ethics: Rules or Standards?
}

\author{
Raymond Floyd \\ Physical Science Division \\ Northwest College \\ Powell, Wyoming
}

\begin{abstract}
Most professional organizations have some form of ethical behavior definition. It may be in the form of a code of conduct, code of ethics, ethical rules, business conduct or some similar title. Each sets guideline on the expectations of the organization on how their members will behave in the on-going activities in their assignments.

Engineering organizations such as the IEEE, SME, and ASME have published codes outlining the expected ethical effort for their members. These codes of conduct need to be presented and discussed during a student's time in school. A simple assignment discussing the topic, "Is It Ethical to Lie?” can provide some interesting insight and discussion. This paper will illustrate some of the "Code of Conduct" discussions prompted by this assignment.
\end{abstract}

\section{Introduction}

Many organizations, which may include professional organizations, trade associations, business organizations, government organizations, and others may have some type of Code of Conduct, Ethical Rules, Mission Statements, or some similar set of concepts that members/employees are expected to follow. The Illinois Institute of Technology Center for the Study of Ethics in the Professions lists almost 100 pages of organizations with some form of ethical rules [1]. Their list is divided into four general categories and cover more than 90 fields from Agriculture to Wildlife and Environmental Stewardship. In each organization, there may be one or more sets of guidelines that the member is expected to follow. Some may have both a code of conduct and a code of ethics.

In the undergraduate class, "Introduction to Engineering," there is a session on ethics. An interesting topic is "Is it Ethical to Lie?" The immediate reaction from the students is a resounding "No!” The next question is, "Is that response based on moral or ethical grounds?" At this point the students aren't sure of the difference between the two words - morals and ethics. Looking at a common dictionary does not provide much help. In one definition for ethics, it is given as 1) the principles of conduct governing an individual or a group, 2) the discipline dealing with what is good and bad and with moral duty and obligation, and 3) a set of moral principles [2]. Likewise, for morals: 1) a doctrine or system of moral conduct, or 2) moral principles or rules of conduct. Note the similarity of the two. As a matter of fact, ethics and morals are frequently interchanged in use as a result. However, there is a fine line of difference in modern usage. The next question that might be asked is "Are ethics a standard that must be followed, or a rule that must be obeyed?” 


\section{Discussion}

Morals are most often engrained into the individual at an early age. "You should not lie," "Don't steal from others," "Be kind to your neighbors," and similar things one should do to be a good person in society. In some cases, the adage might be more strongly worded, "Thou shall not...," almost a rule that must be followed. Morals seldom change with the passage of time. On the other hand, ethics may change with time and/or public opinion. For example, slavery was ethically acceptable to society for hundreds of years (even when morally abhorrent to individuals). That has changed such that the concept of slavery is no longer ethically acceptable in most civilized areas. A second example in how ethical actions change over time is in physician-assisted suicide. Twenty years ago, such a practice was considered unethical, not to mention against existing law. Today, six states have assisted suicide practice as acceptable ethically acceptable now. Where does that place physicians and their code of ethics?

The class discussions moved from the difference between ethics and morals to discussions on codes being rules or standards of behavior. Once more going to the dictionary for both rule and standard, the following were found. First, rule offered: 1) a set of explicit regulations or principles governing conduct within a particular activity, 2) the normal or customary state of things, and 3) pronounce authoritatively and legally to be the case. In the case of standard, 1) a level of quality or attainment, 2) an idea used as a measure, norm, or model in comparative evaluations, and 3) used or accepted as normal or average. From the two definitions, it appears that rule is more explicit and rigid, standard having some measurable flexation permitted, somewhat like the fine line between morals and ethics. In looking at several professional codes of conduct or ethical standards [3, 4], the statements were frequently written as if they were rules, but certain words might be included that moved the statement from a rule to more of a standard, permitting an individual's perception. In other words, the phrase "perceived harm" now relies on the perception of the individual; there is no hard and fast rule. Most of the United States codes included a preamble that noted the codes were "guides" for the membership. Few had any indication of punishment to be merited out if the member violated one of the codes (the worst noted was expulsion from the organization). The exception to that was the Canadian reference [4] that included the comment that violations would be handled under the law provisions of the responsible organization - a much stiffer enforcement mechanism.

Another point of discussion centered on the fact that adoption of a code of conduct or ethical rules does not guarantee that everyone covered by that set of rules will act in an ethical manner. Again, the interpretation is that of individuals and their perceptions of the rule and the particular action being undertaken. It may also be in the interpretation as to the manner of enforcement of the rule - what is the harm if the rule is broken? What enforcement mechanism is in place to ensure that the rule is interpreted uniformly across the organization? Even the threat of expulsion from an organization may not be an effective preventative for someone violating the standard/ethic.

\section{Conclusion}

For the question of whether lying was ethical, the consensus of several classes was that it was not ethical to lie, but there were circumstances that would make it acceptable, with the underlying principle - do no harm. As for the question of whether the codes of ethics were rules or standards, the consensus was that the statements were written more as a standard, where the standard was to achieve some level of personal accomplishment in working to the perceived 
wording of the standard. It was also understood that the codes of ethics had to be written as living documents, as public opinion, over time, shapes the perception of ethical accomplishment. Based on the open discussions that have taken place in the class, it is recommended that discussions on ethics be included as part of all engineering students' course of study.

\section{References}

[1] Illinois Institute of Technology, Center for the Study of Ethics in the Professions, 2019. [Online]. Available: http://ethics.iit.edu/ecodes/node/5621.

[2] Webster’s Ninth New Collegiate Dictionary. Springfield, MA: Merriam-Webster Inc., 1991.

[3] Association for Institutional Research, “AIR Statement of Ethical Principles,” 2020. [Online]. Available: http://www.airweb.org/ir-data- professional-overview/code-of-ethics-and-professional-practice.

[4] Gordon Andrews, Patricia Shaw, and John McPhee, Canadian Professional Engineering and Geoscience: Practice and Ethics, 6th ed. Toronto, Canada: Nelson Education Ltd, 2018.

\section{Biographical Information}

RAYMOND E. FLOYD (M'63 - SM'85 - LSM'03) He has a BSEE from Florida Institute of Technology, Melbourne, FL (1970), an MSEE from Florida Atlantic University, Boca Raton, FL (1977), and a PhD in Engineering Management from California Coast University, Santa Ana, CA (2009). He spent 26 years with IBM, retiring as a senior engineer in 1992. He is currently a visiting lecturer at Northwest College in Powell, WY, where he teaches engineering, programming, and mathematic courses. He most recently co-authored a text, Perspectives on Engineering (2011), an IEEE eBook, Shaping an Engineering Career: Book 2: Dual Career Ladders (2013), and another text, So You Want to be an Engineer? (2015). 